\title{
Effectiveness of a community-delivered pneumatic machine resistance training programme (Gym Tonic) for older adults at neighbourhood senior centres - a randomized controlled trial
}

\author{
Shuen Yee Lee ${ }^{1}$, Alycia Goh², Ken Tan², Pei Ling Choo ${ }^{1,3}$, Peck Hoon Ong ${ }^{1}$, Wai Pong Wong ${ }^{1}$ and
} Shiou-Liang Wee (1, $^{1 *}$

\begin{abstract}
Background: Resistance training with pneumatic machines attenuates the age-associated loss in muscle strength and function in older adults. However, effectiveness of scaled-up pneumatic machine resistance training in the community is not known. We evaluated the effectiveness of a multi-site community-delivered 12-week pneumatic machine resistance programme (Gym Tonic (GT)) on muscle strength and physical function in older adults.

Methods: Three hundred eighteen community-dwelling older adults aged $\geq 65$ years were randomized into $12-$ week (twice/week) coach-supervised-community-based-GT-programme $(n=168)$ and wait-list control groups $(n=$ 150). After 12 weeks, the intervention group continued with GT-training and the control group received supervisedGT-programme for further 12 weeks (partial-crossover-design). Fried frailty score, lower-extremity muscle strength and physical function (i.e., fast and habitual gait-speed, balance, repeated-chair-sit-to-stand, short physical performance battery (SPPB)) were determined at baseline, 12 and 24 weeks. Analysis adopted a modified-intentionto-treat-approach.

Results: After 12 weeks, lower-extremity muscle strength improved by $11-26 \%(a l l p<0.05)$ and fast gait-speed improved by $7 \%(p=0.008)$ in GT-intervention group $(n=132)$ than controls $(n=118)$, regardless of frailty status. Other physical function performance did not differ between control and intervention groups after 12 weeks (all $p>$ $0.05)$. Frailty score improved by 0.5 in the intervention but not control group $(p=0.004)$. Within the intervention group, lower-extremity muscle strength and physical function outcomes improved at 24 weeks compared with baseline (all $p<0.001$ ). Within controls, lower-extremity muscle strength, SPPB, repeated-chair-sit-to-stand and fast gait-speed improved post-GT (24-week) compared to both pre-GT (12-week) and baseline. Programme adherence was high in intervention $[0-12-$ weeks,90\%(SD,13\%); 12-24-weeks,89\%(SD,17\%)] and control [12-24-

weeks,90\%(SD,19\%)] groups.
\end{abstract}

\footnotetext{
* Correspondence: weeshiouliang@gmail.com

'Health and Social Sciences Cluster, Singapore Institute of Technology,

Singapore, Singapore

${ }^{4}$ Geriatric Education and Research Institute, Singapore, Singapore

Full list of author information is available at the end of the article
}

C C The Author(s). 2021 Open Access This article is licensed under a Creative Commons Attribution 4.0 International License, which permits use, sharing, adaptation, distribution and reproduction in any medium or format, as long as you give appropriate credit to the original author(s) and the source, provide a link to the Creative Commons licence, and indicate if changes were made. The images or other third party material in this article are included in the article's Creative Commons licence, unless indicated otherwise in a credit line to the material. If material is not included in the article's Creative Commons licence and your intended use is not permitted by statutory regulation or exceeds the permitted use, you will need to obtain permission directly from the copyright holder. To view a copy of this licence, visit http://creativecommons.org/licenses/by/4.0/ The Creative Commons Public Domain Dedication waiver (http://creativecommons.org/publicdomain/zero/1.0/) applies to the data made available in this article, unless otherwise stated in a credit line to the data. 
Conclusion: Community-delivered GT resistance training programme with pneumatic machines has high adherence, improves muscle strength and fast gait-speed, and can be effectively implemented at scale for older adults. Future studies could examine if including other multi-modal function-specific training to complement GT can achieve better physical/functional performance in power, balance and endurance tasks.

Trial registration: ClinicalTrials.gov, NCT04661618, Registered 10 December 2020 - Retrospectively registered.

Keywords: Technology, Program evaluation, Community-dwelling, Physical function, Community exercise program, Muscle strength

\section{Background}

Ageing is associated with progressive loss in muscle mass and strength, especially in weight-bearing lower limb muscle groups, resulting in a decline in physical function $[1,2]$. The gradual loss in muscle strength and function with age result in adverse health outcomes including frailty, increased risk of falls, lower quality of life, increased dependency, hospitalization and mortality [3, 4]. While multiple factors such as malnutrition, obesity and hormonal changes contribute to the age-associated decline in physical function, low level of physical activity (PA) is a key factor that mediates the reduction in muscle strength and function with age [5].

Despite the well acknowledged benefits of exercise on physical function and health, exercise participation in older adults remains low in many countries, including Singapore [6, 7]. Plausible factors contributing to low exercise participation rates include low accessibility of facilities, safety concerns and lack of adequate guidance with certain training modality such as resistance training [6-8]. To promote exercise participation, it is pertinent for PA research to move beyond clinical research trials to evaluate effectiveness of large-scale communitydelivered programmes.

Resistance exercise, which consists of short-duration activity at high intensities of a few repetitions, is a commonly recommended exercise modality to increase muscle mass, strength, reduce frailty, maintain physical function and mobility in older adults $[9,10]$. Pneumatic machines have been promoted for resistance training in older adults, as the use of compressed air to confer resistance results in reduced stress on joints, lower risk of injury and increased safety [11]. Furthermore, pneumatic machines allow older adults to scale the weight increments in smaller intervals (e.g., $100 \mathrm{~g}$ ) than conventional plate-loaded machines, to better cater to needs of physically frail older adults. However, community-dwelling older adults have limited access to these machines, as these machines are often limited to more exclusive facilities (such as hospitals) due to its high costs and need for maintenance and support equipment, including compressor and pneumatic lines.
Compared with pneumatic machines, an acute exercise bout with conventional plate-loaded machines was of lower intensity and resulted in increased fatigue, suggesting that resistance training with pneumatic machines may be more appropriate for improving muscle strength and function in community-dwelling older adults [12, 13]. Gym Tonic (GT) programme has been implemented at nursing homes and community senior centres, in various locations around Singapore. The charity Lien Foundation initiated and scaled-up GT-programme and appointed a local aged care/health technology provider, PulseSync, to implement the programme and train coaches on the equipment, software, exercise and assessment protocols. The coaches were either exercise trainers, physiotherapists or therapy assistants. Through structured and supervised training, GT is designed to maintain physical strength and extend functional life years in older adults. GT uses pneumatic machines with standardized assessment protocols and an automated system with radio-frequency identification technology, to monitor training progress of participants and adjust the exercise load accordingly [14].

To our knowledge, no study has evaluated the effectiveness of a large multi-site community-delivered pneumatic machine resistance programme. This study evaluates the effects of the 12-week coach-led GTtraining-programme implemented at three neighbourhood senior centers on muscle strength and physical function of older adults.

\section{Methods}

\section{Study design}

PulseSync adopted a randomized controlled design to implement the 12-week coach-led GT intervention to three community senior centers. After 12 weeks, the wait-list control group received the coach-led GTprogramme for a subsequent 12 weeks, in a partial crossover design. The original intervention group had access to GT facility for a further 12 weeks (Fig. 1). Study outcomes were measured at baseline, 12 weeks and 24 weeks. All study visits were conducted across three senior centers at different residential estates in Singapore between Oct 2018 to Jul 2019 (ClincalTrials.gov 


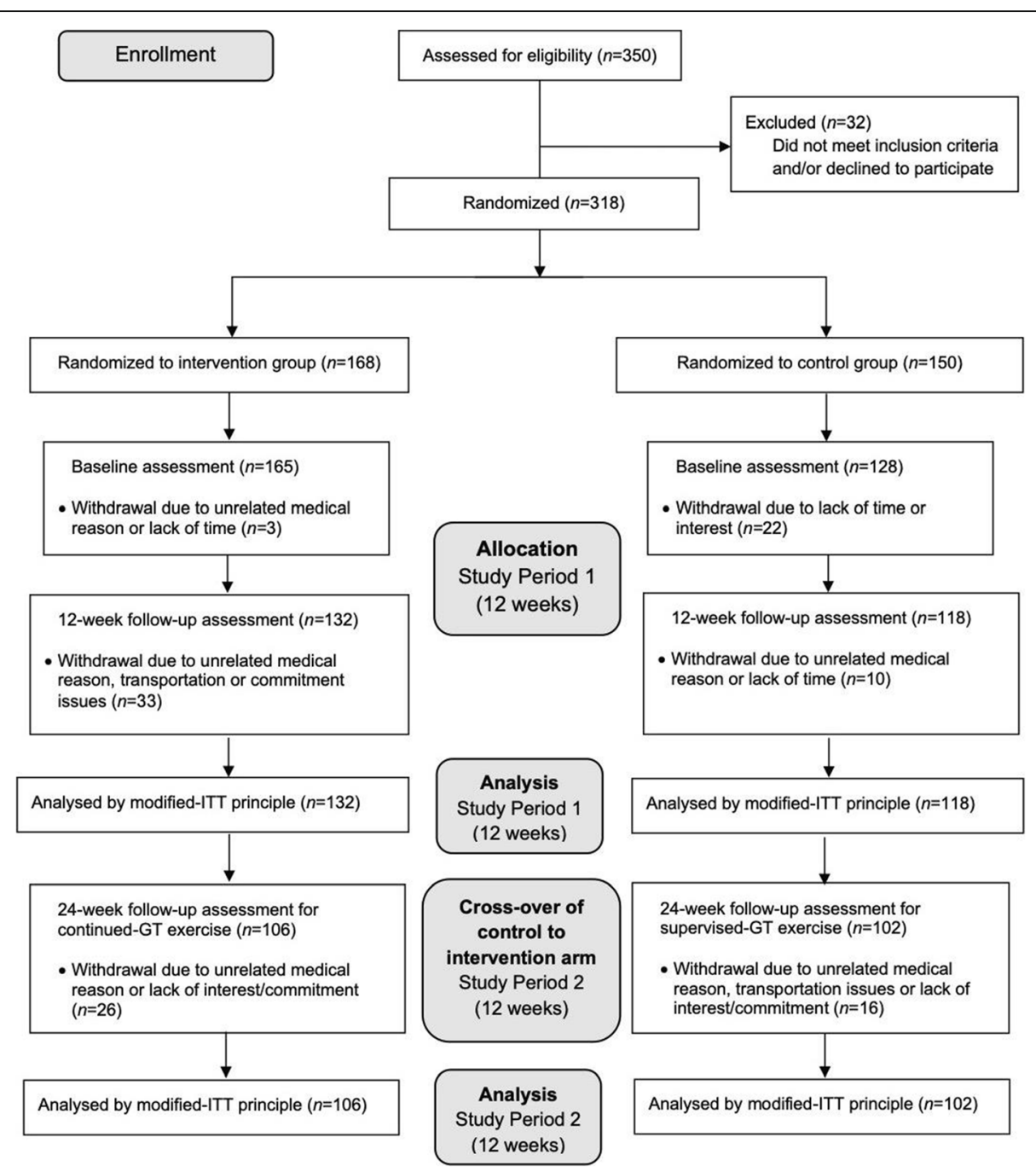

Fig. 1 CONSORT diagram of the randomized controlled trial with crossover of control group to intervention arm after 12 weeks. GT= Gym Tonic programme, ITT = intention-to-treat

Identifier: NCT04661618, retrospectively registered). All participants gave written informed consent. Researchers at Singapore Institute of Technology conducted retrospective analyses and evaluation of the study data collected by PulseSync. Ethics approval was obtained from the institutional review board of Singapore Institute of Technology (IRB-2020178).

\section{Participants}

Community-dwelling adults aged 65 and above were recruited by Lien Foundation, PulseSync and the respective senior centres through publicity on a local radio programme and word of mouth. Respondents who were ambulant with or without the use of walking aid, and without severe cognitive impairment (i.e., Cognitive performance scale $<3$ or Mini-mental state examination $>$ 18 ), heart and pulmonary conditions or conditions that were contraindicative to exercise, were screened and included in the GT-programme by coaches at the respective centres. For two of the three centres, participants were randomised 1:1 to intervention or control groups in blocks of 4 or 10 using a computer-generated randomization list, by coaches. For the last centre, randomization was unequal (3:2) with a larger intervention group, as more respondents were unwilling to wait for 12 weeks prior to exercise intervention. Group allocation was concealed until participants were enrolled. Neither participants nor assessors were blinded to the intervention allocation.

\section{Intervention}

The exercise intervention consisted of twice-weekly coach-supervised progressive resistance training for 12 weeks, with a maximum coach-to-participant ratio of 1 : 6 . The exercises included chest press, lat pulldown, abdomen, back extension, leg press, leg extension, leg curl, 
hip abduction and hip adduction, which target major upper and lower body muscle groups. Within the 12week training period, participants underwent 2-week training at $15 \mathrm{RM}$ for 2 sets of 15 repetitions $(\sim 60 \%$ $1 \mathrm{RM})$. For the subsequent 5 weeks, each training session involved a workload at $10 \mathrm{RM}$ for 2 sets of 10 repetitions ( 70\% 1RM). During the last 5 weeks, participants performed a workload of $8 \mathrm{RM}$ for 2 sets of 8 repetitions ( $80 \% 1 \mathrm{RM})$ [9]. The intensity, volume and progression of training were based on the current recommended resistance training guidelines for older adults $[9,15]$. A minimum of $15 \mathrm{~s}$ recovery was provided between sets. The load increment was determined by coaches, ranging from $0.1-1 \mathrm{~kg}$ when participants could perform 2 additional repetitions per set.

After the initial 12-week wait, the control group completed the same 12-week GT-programme. Participants in the original intervention group continued a further 12 weeks of GT training, involving 3 sets of 10 repetitions at $10 \mathrm{RM}$ twice-weekly. All exercises were performed using pneumatic machines (HUR, Kokkola, Finland).

\section{Outcomes}

\section{Anthropometric and cardiovascular}

Anthropometric measures included body weight, height, body mass index (BMI) and waist circumference. Blood pressure and heart rate were measured with an automated device (Omron Corporation, Kyoto, Japan). All measures were performed by the senior centre coaches.

\section{Muscle strength}

Handgrip strength was measured with participants seated with arms unsupported, elbow joint at 90 degrees and wrist in a neutral position while holding the hand dynamometer (Jamar Plus+, Patterson Medical, Cedarburg, WI). The highest reading of three trials per arm with 30s rest intervals was reported. Lower body muscle strength was measured using $1 \mathrm{RM}$ for left and right knee flexion and extension, hip abduction and hip adduction in both limbs (HUR, Kokkola, Finland), with the highest reading of three trials reported. All muscle strength assessments were also conducted by respective coaches at each senior centres.

\section{Physical function}

Physical function was assessed by the respective trained coaches at each senior centre, using the short physical performance battery (SPPB) and fast gait speed (GS). SPPB assesses lower limb function, including balance, strength and mobility. SPPB consisted of 3 subtests (balance, habitual GS and sit-to-stand time) [16]. The balance subtest comprised 3 parts each with progressive difficulty, including unaided feet-together stand, semitandem stand and full-tandem stand. Participants were timed until they moved or maximum of 10s. The repeated-chair sit-to-stand assessment involved a pretest to determine if participants could stand up from the chair with arms across chest. Participants were timed while performing five chair stands as quickly as possible. Habitual GS was calculated by timed walk of $4 \mathrm{~m}$ at usual pace. To account for acceleration and deceleration, markers were provided $1.5 \mathrm{~m}$ before and after the measured distance. Each of the 3 subtests was scored from 0 to 4 and the total score was the sum of 3 subtests, ranging from 0 to 12 . Higher SPPB scores indicated better physical function [16]. Fast GS was similarly assessed by determining participants timed walk over $4 \mathrm{~m}$, as fast and comfortably able, with a moving start.

\section{Frailty status}

Frailty status was assessed using Fried's Frailty phenotype, which defines frailty based on presence of five components: weakness, unintentional weight loss, slowness, exhaustion and low PA [17]. Weakness was determined using the Asian Working Group for Sarcopenia hand grip strength criteria of $<26 \mathrm{~kg}$ for men and $<18$ $\mathrm{kg}$ for women [18]. Unintentional weight loss was defined as weight loss of $\geq 4.5 \mathrm{~kg}$ in 6 months or BMI $\leq 18.5 \mathrm{~kg} / \mathrm{m}^{2}$. Slowness was identified as habitual walking speed $(4 \mathrm{~m})$ stratified by sex and height [17]. Exhaustion was determined through a self-reported 2-item questionnaire adapted from the Centre for Epidemiologic Studies Depression [19]. Participants were classified as low PA if they engaged in less than once per week of at least 30mins of self-reported moderate-to-vigorous-intensity PA $[17,20]$. Participants were classified into frailty status based on presence of number of components: robust (0), pre-frail $(1,2)$ and frail $(3-5)$.

\section{Statistical analysis}

All statistical analyses were performed using $\mathrm{R}$ version 3.6.2 ( $\mathrm{R}$ Foundation for statistical computing, Vienna, Austria). A sample size of 200 (100 per group) was needed for the trial to have $80 \%$ power to detect a twosided hypothesis test at an $\alpha$ level of 0.05 (effect size of 0.2) (G*Power, version 3.1, Germany). After allowing for a 30\% drop-out rate, the planned sample size was 150 participants per group. All participants with completed outcome measures at baseline and 12 weeks were included for analysis according to their randomized group allocation (modified intention-to-treat analysis), and maximum likelihood estimation was used to analyse missing data. Numerical variables are presented as mean (standard deviation, SD) in text and figures unless otherwise stated. Independent samples t-test was used to compare differences in participant characteristics between control and intervention groups. Between-group differences for physical function, muscle strength, 
anthropometric and cardiovascular outcomes measured from baseline to 12 weeks were analysed using mixedeffect model with Group, Time, and their interactions as fixed effects and subject as random effect. For betweengroup effects of frailty status on physical function and muscle strength across 12 weeks, a similar mixed-effect model with Group, Time, Frailty status, and their interactions as fixed effects and subject as random effect was used. All mixed-effect models were adjusted for age, sex and moderate-to-vigorous-PA levels at baseline. Bonferroni adjustment was used for comparison of timepoints (baseline-12 weeks) between groups. Within-group differences for pre- to post-GT in the entire cohort were analysed using the paired t-test. One-way ANOVA with Bonferroni adjustment was used to analyse within-group differences in outcome measures from baseline to 12 and 24 weeks. A value of $p<0.05$ was considered statistically significant.

\section{Results}

\section{Participant characteristics}

Three hundred eighteen participants were recruited and randomized into intervention $(n=168)$ and wait-list control $(n=150)$ groups. Prior to baseline measurement, $3(2 \%)$ and $22(15 \%)$ participants withdrew from the intervention and control groups respectively, due to unrelated medical conditions, lack of time or interest (Fig. 1). A total of 165 (75.8\% women) and 128 (72.7\% women) participants in the intervention and control groups completed baseline assessment respectively. From baseline to 12 weeks, 33(20\%) participants from the intervention group and $10(8 \%)$ participants from the control group withdrew, due to unrelated medical conditions, transportation or commitment issues. After 12 weeks, 132 (77.3\% women) and 118 (72.9\% women) participants started and completed the GT intervention and control phase, respectively, and had outcome data for analysis (Fig. 1). Between week 12-24, 102 participants (72.5\% women) from the original control group completed the GTprogramme, allowing for a total of 234 participants in the longitudinal analysis. From week 12-24, 106 participants $(77.4 \%$ women) from the original intervention group continued and completed the GT-programme (Fig. 1).

Among participants who completed post-testing, mean adherence to 12-week GT-programme was $90 \%(\mathrm{SD}, 13 \%)$ for intervention (baseline-12 weeks), 89\%(SD,17\%) for wait-list control (12-24 weeks) groups, and 90\%(SD,19\%) for intervention (12-24 weeks) group.

Participant baseline characteristics are presented in Table 1, with no difference between groups, apart from PA. Intervention group engaged in $\sim 0.5$ more days/week of $\geq 30 \mathrm{~min}$ of moderate-to-vigorous-intensity $\mathrm{PA}$ at baseline $(p=0.02)$. The results presented did not differ
Table 1 Mean (SD) Participant characteristics at baseline in control and intervention groups

\begin{tabular}{llll}
\hline & Control & Intervention & $P$ value \\
\hline$n$ & 128 & 165 & \\
Sex, Female (n (\%)) & $92(74 \%)$ & $125(76 \%)$ & \\
Age (years) & $73(6)$ & $73(7)$ & 0.836 \\
Height (cm) & $156(8)$ & $156(8)$ & 0.693 \\
Weight (kg) & $58(12)$ & $57(12)$ & 0.619 \\
Body Mass Index (kg/m2) & $23.7(4.1)$ & $23.4(4.2)$ & 0.493 \\
Waist Circumference (cm) & $86.5(11.3)$ & $86.8(11.6)$ & 0.818 \\
Systolic BP (mmHg) & $130(16)$ & $129(17)$ & 0.668 \\
Diastolic BP (mmHg) & $76(10)$ & $77(10)$ & 0.816 \\
Heart Rate (bpm) & $73(11)$ & $73(11)$ & 0.945 \\
Mod/Nig Physical Activity (days/wk) & $1.0(1.8)$ & $1.5(2.1)$ & $0.02^{*}$ \\
Frailty Status (\%) & & & \\
$\quad$ Robust & 24 & 23 & \\
$\quad$ Pre-Frail & 56 & 61 & \\
$\quad$ Frail & 20 & 16 & \\
\hline Mod Moderate intensity, Vig Vigorous intensity, ${ }^{*} p<0.05$ &
\end{tabular}

across community senior centres; hence, data are presented with centre excluded from the model.

\section{Anthropometry, cardiovascular and frailty status}

After 12 weeks, individuals in the intervention group had $2 \%$ decrease in waist circumference, which was not apparent in controls (Group $\times$ Time; $p=0.015$,Table 2). Cardiovascular outcomes did not differ between groups after 12 weeks (Table 2). Frailty score improved by 0.5 points in the intervention group but not the control group after 12 weeks (Group $\times$ Time; $p=0.004$,Table 2).

\section{Muscle strength}

Hand grip and left knee extension strength did not differ between control and intervention group after 12 weeks (Group $\times$ Time; $p>0.05$, Table 2). After 12 weeks, right knee extension increased by $15 \%$ among the intervention group (Group $\times$ Time; $p=0.01$, Table 2). Knee flexion strength increased by $19-26 \%$, and hip abduction and adduction strength increased by $11-14 \%$ after 12 weeks in the intervention but not control group (Group $\times$ Time; $p<0.001$,Table 2). Left and right knee extension and flexion, hip abduction and adduction strength increased after 12- and 24-week GT-programme, compared with baseline in the intervention group (Fig. 2a, c, e), and post-GT (24-week) compared with both baseline and pre-GT (12-week) in the control group (Fig. 2b, d, f).

Among 234 participants from both groups who completed the 12-week GT-programme, knee extension and flexion, hip abduction and adduction strength increased by $10-20 \%$ (all $p<0.001$, Fig. S1). Baseline frailty status 
Table 2 Mean (SD) Study outcomes at 12 weeks in GT-intervention and control groups

\begin{tabular}{|c|c|c|c|c|c|c|c|}
\hline & \multicolumn{2}{|c|}{ Control $(n=118)$} & \multirow[b]{2}{*}{ Change } & \multicolumn{2}{|c|}{ Intervention $(n=132)$} & \multirow[b]{2}{*}{ Change } & \multirow{2}{*}{$\begin{array}{l}P \text { value } \\
\text { Group } \times \\
\text { Time }\end{array}$} \\
\hline & Baseline & 12-week & & Baseline & 12-week & & \\
\hline \multicolumn{8}{|l|}{ Anthropometric } \\
\hline Weight (kg) & $57.9(11.8)$ & $57.8(11.8)$ & $-0.1(1.1)$ & $56.7(11.8)$ & $57.0(11.8)$ & $0.3(1.4)$ & 0.054 \\
\hline Body Mass Index (kg/m2) & $23.6(3.8)$ & $23.6(3.9)$ & $0.0(0.5)$ & $23.1(4.3)$ & $\begin{array}{l}23.2 \\
(4.4)\end{array}$ & $0.1(0.6)$ & 0.034 \\
\hline Waist Circumference (cm) & $86.3(11.5)$ & $86.4(10.7)$ & $0.1(5.0)$ & $86.1(11.9)$ & $84.5(12.0)^{* *}$ & $-1.6(5.7)$ & 0.015 \\
\hline \multicolumn{8}{|l|}{ Cardiovascular } \\
\hline Systolic BP (mmHg) & $130(16)$ & $129(16)$ & $-2(15)$ & $130(17)$ & $128(13)$ & $-1(14)$ & 0.842 \\
\hline Diastolic BP (mmHg) & $76(10)$ & $75(9)$ & $-1(8)$ & $76(10)$ & $75(9)$ & $-2(8)$ & 0.275 \\
\hline Heart rate (bpm) & $73(11)$ & $74(13)$ & $1(9)$ & $74(11)$ & $76(11)$ & $2(8)$ & 0.416 \\
\hline \multicolumn{8}{|l|}{ Muscle Strength } \\
\hline Hand Grip (kg) & $21.3(6.4)$ & $21.5(6.3)$ & $0.2(2.3)$ & $21.3(6.9)$ & $\begin{array}{l}21.4 \\
(6.3)\end{array}$ & $0.1(2.8)$ & 0.616 \\
\hline Knee Extensor Left (kgf) & $52.7(19.8)$ & $56.6(22.8)$ & $4.0(14.1)$ & $54.4(22.0)$ & $60.9(22.9)$ & $6.6(14.4)$ & 0.148 \\
\hline Knee Extensor Right (kgf) & $53.2(21.8)$ & $56.7(21.7)^{*}$ & $3.6(11.7)$ & $53.4(20.5)$ & $61.6(22.2)^{* * *}$ & $8.2(15.9)$ & 0.010 \\
\hline Knee Flexion Left (kgf) & $27.3(11.5)$ & $28.9(12.2)$ & $1.5(7.3)$ & $27.2(13.0)$ & $32.4(13.8)^{* * *}$ & $5.2(8.5)$ & $<0.001$ \\
\hline Knee Flexion Right (kgf) & $26.9(26.5)$ & $28.2(12.8)$ & $1.2(9.2)$ & $26.5(11.9)$ & $33.3(13.5)^{* * *}$ & $6.8(9.2)$ & $<0.001$ \\
\hline Hip Abduction (kgf) & $43.8(13.3)$ & $44.3(13.8)$ & $0.5(7.0)$ & $44.7(14.0)$ & $49.4(14.6)^{* * *}$ & $4.6(7.0)$ & $<0.001$ \\
\hline Hip Adduction (kgf) & $47.6(17.2)$ & $49.4(18.8)$ & $1.8(8.7)$ & $47.9(16.4)$ & $54.8(19.0)^{* * *}$ & $6.9(9.6)$ & $<0.001$ \\
\hline \multicolumn{8}{|l|}{ Physical Function } \\
\hline 5x Sit-to-stand (s) & $13.4(7.7)$ & $12.9(9.0)$ & $-0.4(4.1)$ & $12.6(5.7)$ & $11.1(5.3)$ & $-1.2(3.9)$ & 0.105 \\
\hline Habitual Gait Speed (m/s) & $0.93(0.34)$ & $1.00(0.33)$ & $0.06(0.22)$ & $0.95(0.29)$ & $1.04(0.35)$ & $0.10(0.22)$ & 0.267 \\
\hline Fast Gait Speed (m/s) & $1.35(0.51)$ & $1.37(0.48)$ & $0.02(0.30)$ & $1.31(0.39)$ & $1.40(0.48)^{* * *}$ & $0.11(0.26)$ & 0.008 \\
\hline Balance Score & $3.46(1.05)$ & $3.64(0.79)$ & $0.17(0.89)$ & $3.53(0.92)$ & $3.54(0.99)$ & $0.07(0.75)$ & 0.252 \\
\hline SPPB Score & $9.7(3.0)$ & $10.3(2.6)$ & $0.5(1.6)$ & $10.1(2.5)$ & $10.5(2.7)$ & $0.5(1.3)$ & 0.861 \\
\hline Fried Frailty Score & $1.52(1.16)$ & $1.34(1.08)$ & $-0.16(0.78)$ & $1.40(1.07)$ & $0.96(1.05)^{* * *}$ & $-0.49(0.89)$ & 0.004 \\
\hline
\end{tabular}

${ }^{*} p<0.05,{ }^{* *} p<0.01,{ }^{* * *} p<0.001$ significant at 12-week compared to values at baseline within group; Bold type interface indicates significant interaction effect (Group $\times$ Time), $p$ values adjusted for age, sex and physical activity levels at baseline

did not affect right knee extension, left and right knee flexion, hip abduction and adduction strength between groups from baseline-12 weeks (all $p>0.05$ ). In pre-frail individuals only, the increase in left knee extension strength was apparent in the intervention $(19 \%, p<$ $0.001)$ but not control group (6\%, $p=0.237)$ (Group $\times \mathrm{Ti}-$ mexFrailty; $p=0.013$ ).

\section{Physical function}

Repeated chair sit-to-stand time, habitual GS and SPPB total score did not differ between intervention and control groups after 12 weeks (Group $\times$ Time;all $p>$ 0.05 ,Table 2). Within intervention group, SPPB, sit-tostand and habitual GS improved at 12 and 24 weeks than baseline (all $p<0.01$,Fig. 3a, c, e). Within control group, SPPB and sit-to-stand improved post-GT (24-weeks) compared with pre-GT (12-weeks) and baseline (all $p<0.05$,Fig. 3b, d), while habitual GS improved post-GT (24-weeks) compared with baseline only ( $p<0.001$, Fig. 3f). Balance score from baseline to 12 weeks did not differ between groups (Group $\times$ Time; $p=0.252$, Table 2). Balance score did not differ within intervention group across 24 weeks (all $p>0.05$ ). Within controls, balance score improved post-GT (24-weeks) compared to baseline $(p=0.02)$.

After 12 weeks, fast GS increased by $7 \%$ in the intervention but not the control group (Group $\times$ Time; $p=$ 0.008 ,Table 2). Within the intervention group, fast GS at 24-weeks post-GT was higher than both 12-weeks postGT $(p=0.02)$ and baseline $(p<0.001)$ (Fig. 3e). Within the control group, fast GS was higher post-GT (24weeks) than both pre-GT (12-weeks) $(p=0.037)$ and baseline $(p=0.004)$ (Fig. 3f).

Among all 234 participants who completed the 12week GT-programme, SPPB and sit-to-stand improved by $3.6 \%$ and $11.7 \%$ respectively, while habitual and fast GS improved by $6.0 \%$ (all $p<0.001$, Fig. S2a-d). Balance score did not differ after 12-week GT ( $p=0.131$, Fig. 


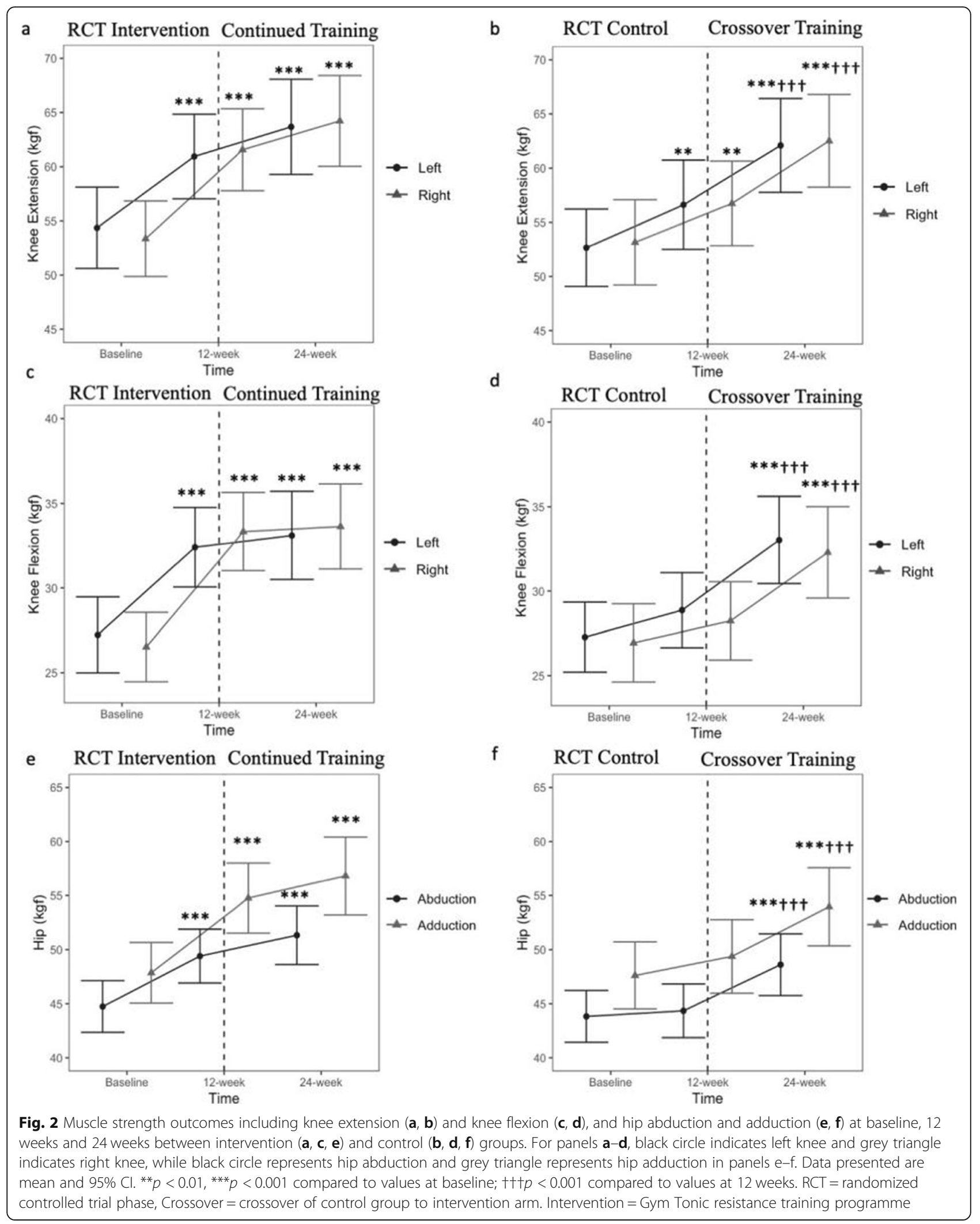




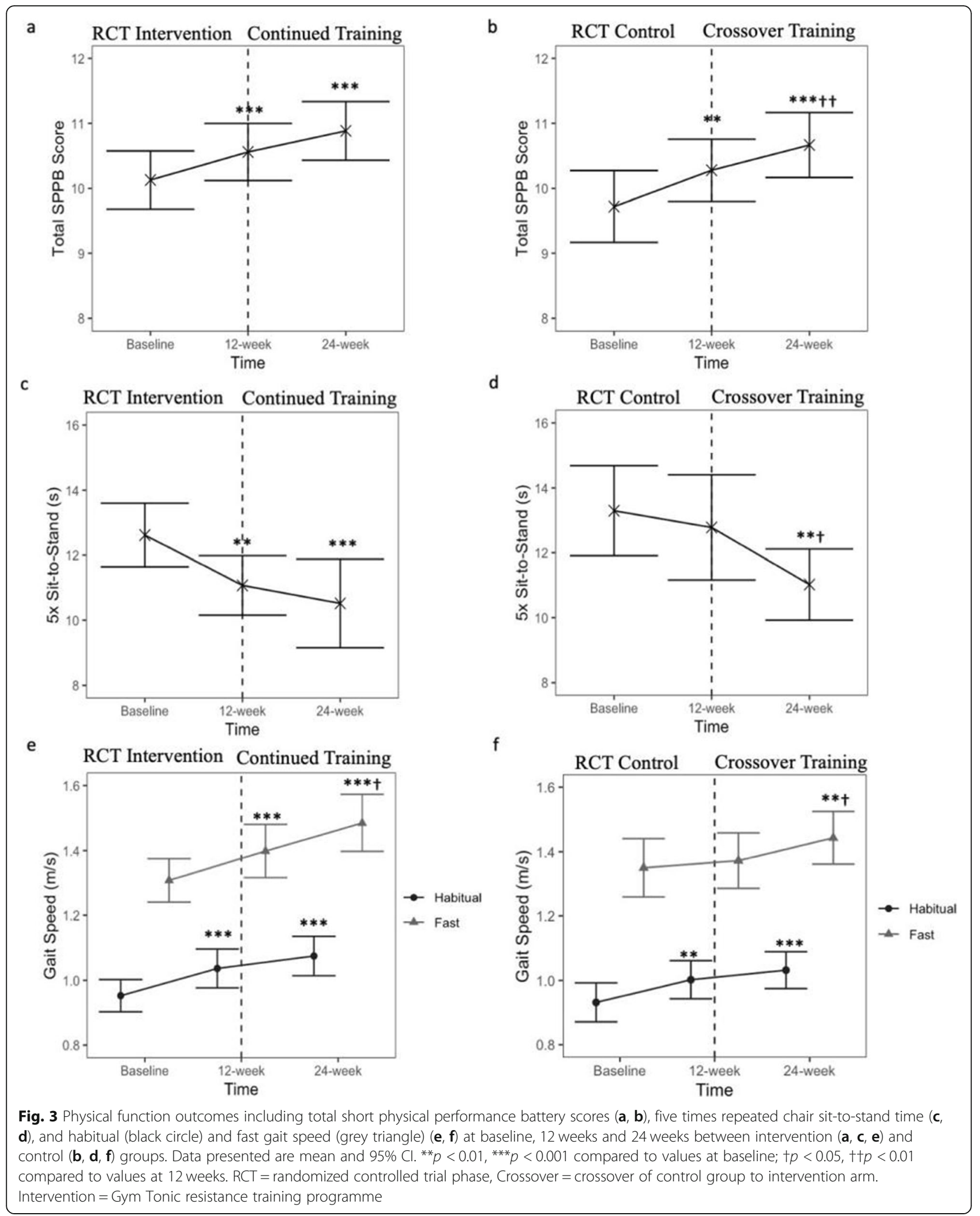


S2e). Physical function measures between groups did not differ by baseline frailty status after 12 weeks (all $p>$ $0.05)$.

\section{Discussion}

The present study is the first to evaluate the effectiveness of multi-site community-delivered 12-week GTprogramme (pneumatic machine resistance training) among older adults. The GT-programme can be implemented in neighbourhood senior centres and is effective in improving muscle strength and fast GS regardless of frailty status. GT-programme provides structured guidance, progression and facility for resistance training in a safe environment, which promotes exercise initiation, adherence and maintenance among community-dwelling older adults.

An increase in muscle strength, especially in lower extremities, is associated with a reduction in fall risk [21], and improvement in physical function, quality of life and mental health in older adults [22]. Compared with controls, our results showed 11-26\% improvement in lower-extremity muscle strength with GT intervention from baseline to 12 weeks. The increase in muscle strength was also maintained after 12-week continuedtraining in the intervention group. Maintaining muscle strength with age is important to reduce associated personal, social and economic burdens [23]. Our results extended the findings of previous small research studies on muscle strength improvement with pneumatic machine resistance training $[24,25]$, to a community programme implemented at multiple neighbourhood senior centres.

GT-programme increased fast GS on average by 0.1 $\mathrm{m} / \mathrm{s}$ in the intervention group compared with controls, from baseline to 12 weeks. GS is an important predictor for fall risk, disability and survival [26-29]. In a large pooled analysis of 34,485 community-dwelling older adults, GS increment of $0.1 \mathrm{~m} / \mathrm{s}$ was clinically significant, resulting in better survival [29]. Accelerated decline in fast GS predicted future disability in older adults, independent of baseline GS [27]. These results suggest that GT-programme-induced improvement in mobility may mitigate some age-associated functional decline, plausibly improving survival and disability among older adults. A systematic review of 24 studies reported that resistance training improved fast gait by a greater extent than habitual GS [30]. In contrast with our findings, a meta-analysis of 16 studies concluded that strength and combination (aerobic and other exercises) training had no effect on fast GS [31]. The disparity in findings could be due to inclusion of studies without a control group [32], and participants from tertiary-care hospitals who were frail and at risk of falls [33], which differed from our randomized controlled study of community-dwelling adults with varying frailty status. Baseline fast GS of GT- programme participants was slightly slower than reference values of community-dwelling older adults of the same age group who were independent in performing activities of daily living [34]. These results imply lower mobility at baseline among GT-programme participants, evidenced by the majority of participants with pre-frailty and frailty, which could explain the clinically significant response of fast gait to GT training. The mechanisms underlying the improvement in fast GS with GT programme may involve an increase in hip extensor and ankle plantar flexor strength with exercise through greater activation of motor units, contributing to improvement in neuromuscular and cognitive function, and in turn resulting in faster GS $[35,36]$.

GT-programme did not significantly affect other measures of physical function performance compared to controls. The programme utilised a single-mode resistance training with pneumatic machines, which might not be as effective as multi-modal exercise, targeted at improving specific functional performance. These findings highlight the importance of training specificity in older adults. In addition to resistance exercise, targeted training programmes for power, flexibility, balance and/ or endurance, can be complementary to mitigate other age-related physical or functional decline [37-39].

Across all GT-programme participants, SPPB, habitual GS and sit-to-stand improved after 12 weeks compared to pre-training, suggesting an increase in physical function, which could improve mobility, disability and quality of life [40]. However, balance performance did not improve with GT-programme. In contrast, earlier studies observed an improvement in balance after 10-12-week resistance training among older adults aged $\geq 65$ years [41, 42]. Unlike earlier studies which measured balance performance on a continuous scale without an upper limit, balance performance in our study might not be sensitive enough to observe improvements with GTprogramme. In agreement with SPPB scores from community-dwelling older Singaporean adults [43], preGT balance scores in this study were also close to maximum $(\sim 3.5)$, which could plausibly decrease the potential for a greater response to the intervention in our population. Given the potential ceiling effects of SPPB and subtest scores, future studies should employ other measures of balance performance and report specific test values instead of ordinal scores.

Higher exercise participation history predicts longterm exercise adherence [44, 45]. In our study, adherence was high $(\sim 90 \%)$ among participants who completed the GT-programme, independent of baseline PA levels. Our findings suggest that community-delivered GT is feasible and engaging, even for participants who were physically inactive at baseline. Also, small-group, supervised and individualised nature of GT-programme 
could plausibly increase exercise adherence [45, 46]. Nonetheless, the drop-out rate for GT-programme across all participants was $13-20 \%$, due to factors such as transportation or commitment, suggesting that environmental factors (e.g., accessibility and flexibility) plausibly influence exercise behaviours among older adults, especially for those with poor mobility [46]. While study participants were not charged for 12-week GT programme, community providers charge a package fee (SGD150-250), with a waitlist at popular sites, showing that the programme has been successfully scaled-up in the community. The present study is a pragmatic randomized controlled trial, which focused on the evaluation of the effectiveness and implementation of GT programme in the real-world setting. Hence, apart from muscle strength and function outcomes, evaluation of adherence and scalability potential of GT programme is also salient.

This community implementation research incorporated a wait-list control design to incentivise retention in the control group and to allow for longitudinal analysis and comparison between pre- and post-GT exercise intervention among the entire cohort. There are limitations owing to nature of implementation. The improvements in muscle strength and function in the control group from baseline to 12-weeks may likely be due to the Hawthorne effect [47], where the participant's behaviour is modified due to awareness of being observed, or the recruitment of highly motivated participants in the control group. Furthermore, the assessments were performed by coaches who were not blinded to the intervention and there was no comprehensive monitoring of adverse events. Our evaluation included robust, pre-frail and frail individuals living in the community, which cannot be generalised to institutionalised older adults. While we adjusted for sex in all analyses, our study participants were mostly women, which is consistent with earlier studies showing that community exercise programmes attract mainly women [37-39]. Future studies should investigate the sex-specific effects on community-delivered pneumatic machine resistance training. Future studies could also compare resistance exercise using pneumatic machines with other exercise types (aerobic, combined etc.) and explore the longerterm effects of continued resistance training on functional performance, risk of falls, disability and mortality in older adults.

\section{Conclusions}

Our findings extend upon earlier laboratory studies on the benefits of resistance training with pneumatic machines on muscle strength and function, that these training programmes have high adherence, can be scaled-up, and be effectively delivered by community providers at neighbourhood senior centres. Future studies could examine if including other multi-modal function-specific training to complement GT-programme can achieve better physical function in other balance, endurance and power-related tasks.

\section{Abbreviations}

BMI: Body Mass Index; GS: Gait Speed; GT: Gym Tonic; PA: Physical Activity; RM: Repetition Maximum; SPPB: Short Physical Performance Battery

\section{Supplementary Information}

The online version contains supplementary material available at https://doi. org/10.1186/s11556-021-00273-x.

Additional file 1: Supplementary Figure S1. Mean and SD of maximal isometric muscle strength outcomes from pre- to post-exercise for all participants $(n=234)$ who undertook 12 weeks of "Gym Tonic" resistance training programme. ${ }^{* *} p<0.001$.

Additional file 2: Supplementary Figure S2. Mean and SD of physical function outcomes from pre- to post-exercise for all participants $(n=234)$ who undertook 12 weeks of "Gym Tonic" resistance training programme. ${ }^{* * *} p<0.001$, ns $=$ not significant. SPPB $=$ Short Physical Performance Battery.

\section{Acknowledgements}

The authors would like to thank the Gym Tonic coaches from Bishan Community Club, Care Corner Senior Services, NTUC Health Serangoon and all the participants for their contribution.

\section{Authors' contributions}

SYL performed the data analysis, interpretation, visualisation and wrote the manuscript. SLW interpreted the data and revised the manuscript. AG, KT contributed to the study concept and design, and acquired the data. PLC, $\mathrm{PHO}$, WPW contributed to the critical revision of the manuscript for important intellectual content. All authors read and approved the final manuscript.

\section{Funding}

Funding: The GT program was funded by Lien Foundation. The evaluation by SIT was partly funded through an Ministry of Education Innovation Capability Fund (R-MOE-A404-F024).

Role of the Funder/Sponsor: Funders played no part in the design or conduct of the study; collection, management, analysis, or interpretation of the data; preparation, review, or approval of the manuscript; or decision to submit the manuscript for publication.

\section{Availability of data and materials}

The datasets used and/or analysed during the current study are available from the corresponding author on reasonable request.

\section{Declarations}

Ethics approval and consent to participate

Ethics approval was obtained from the institutional review board of Singapore Institute of Technology (IRB-2020178). All participants gave written informed consent.

\section{Consent for publication \\ Not applicable.}

\section{Competing interests}

AG and KT are employed by PulseSync, which was responsible for implementing the programme evaluated in the study. AG is the programme executive and KT is the managing director of PulseSync. None of the other authors had any other competing interests. 


\section{Author details}

${ }^{1}$ Health and Social Sciences Cluster, Singapore Institute of Technology, Singapore, Singapore. ${ }^{2}$ PulseSync Pte Ltd, Singapore, Singapore. ${ }^{3}$ School of Health and Life Sciences, Glasgow Caledonian University, Glasgow, UK. ${ }^{4}$ Geriatric Education and Research Institute, Singapore, Singapore.

Received: 4 May 2021 Accepted: 18 September 2021

Published online: 07 October 2021

\section{References}

1. Lopez-Otin C, Blasco MA, Partridge L, Serrano M, Kroemer G. The hallmarks of aging. Cell. 2013;153(6):1194-217. https://doi.org/10.1016/j.cell.2013.05.03 9.

2. Goodpaster BH, Park SW, Harris TB, Kritchevsky SB, Nevitt M, Schwartz AV, et al. The loss of skeletal muscle strength, mass, and quality in older adults: the health, aging and body composition study. J Gerontol A Biol Sci Med Sci. 2006;61(10):1059-64. https://doi.org/10.1093/gerona/61.10.1059.

3. Wolfson L, Judge J, Whipple R, King M. Strength is a major factor in balance, gait, and the occurrence of falls. J Gerontol A Biol Sci Med Sci. 1995;50:64-7.

4. Hunter GR, McCarthy JP, Bamman MM. Effects of resistance training on older adults. Sports Med. 2004;34(5):329-48. https://doi.org/10.2165/000072 56-200434050-00005.

5. Dennison EM, Sayer AA, Cooper C. Epidemiology of sarcopenia and insight into possible therapeutic targets. Nat Rev Rheumatol. 2017;13(6):340-7. https://doi.org/10.1038/nrrheum.2017.60.

6. Justine M, Azizan A, Hassan V, Salleh Z, Manaf H. Barriers to participation in physical activity and exercise among middle-aged and elderly individuals. Singap Med J. 2013;54(10):581-6. https://doi.org/10.11622/smedj.2013203.

7. Beck KL, Weeks LE, Montelpare WJ, MacDonald DJ. Identifying important factors for older adults' physical activity participation across individual/ group, structured/unstructured contexts. Eur J Ageing. 2016;13(3):209-18. https://doi.org/10.1007/s10433-016-0376-1

8. Winett RA, Williams DM, Davy BM. Initiating and maintaining resistance training in older adults: a social cognitive theory-based approach. $\mathrm{Br} J$ Sports Med. 2009:43(2):114-9. https://doi.org/10.1136/bjsm.2008.049361.

9. Fragala MS, Cadore EL, Dorgo S, Izquierdo M, Kraemer WJ, Peterson MD, et al. Resistance training for older adults: position statement from the National Strength and conditioning association. J Strength Cond Res. 2019; 33(8):2019-52. https://doi.org/10.1519/JSC.0000000000003230.

10. Liu X, Ng DH-M, Seah JW-T, Munro YL, Wee S-L. Update on interventions to prevent or reduce frailty in community-dwelling older adults: a scoping review and community translation. Curr Geriatr Rep. 2019;8(2):72-86. https:// doi.org/10.1007/s13670-019-0277-1.

11. Jozsi AC, Campbell WW, Joseph L, Davey SL, Evans WJ. Changes in power with resistance training in older and younger men and women. J Gerontol A Biol Sci Med Sci. 1999;54(11):M591-6. https://doi.org/10.1093/gerona/ 54.11.M591

12. Peltonen $\mathrm{H}$, Häkkinen $\mathrm{K}$, Avela J. Neuromuscular responses to different resistance loading protocols using pneumatic and weight stack devices. J Electromyogr Kinesiol. 2013;23(1):118-24. https://doi.org/10.1016/j.jelekin.2 012.08.017.

13. Napoli NJ, Mixco AR, Bohorquez JE, Signorile JF. An EMG comparative analysis of quadriceps during isoinertial strength training using nonlinear scaled wavelets. Hum Mov Sci. 2015;40:134-53. https://doi.org/10.1016/j. humov.2014.12.009.

14. GymTonic. Exercise becomes potent medicine for the frail elderly in 12 eldercare facilities under Lien Foundation's latest \$2.2m 'Gym Tonic' initiative 2015 Available from: https://www.gymtonic.sg/images/Gym-TonicPress-Kit.pdf.

15. Garber CE, Blissmer B, Deschenes MR, Franklin BA, Lamonte MJ, Lee IM, et al. Quantity and Quality of Exercise for Developing and Maintaining Cardiorespiratory, Musculoskeletal, and Neuromotor Fitness in Apparently Healthy Adults: Guidance for Prescribing Exercise. Med Sci Sports Exerc. 2011;43(7):1334-59.

16. Guralnik JM, Ferrucci L, Simonsick EM, Salive ME, Wallace RB. Lowerextremity function in persons over the age of 70 years as a predictor of subsequent disability. N Engl J Med. 1995;332(9):556-61. https://doi.org/10.1 056/NEJM199503023320902.

17. Fried LP, Tangen CM, Walston J, Newman AB, Hirsch C, Gottdiener J, et al. Frailty in older adults: evidence for a phenotype. J Gerontol A Biol Sci Med Sci. 2001;56(3):M146-56. https://doi.org/10.1093/gerona/56.3.M146.
18. Chen LK, Liu LK, Woo J, Assantachai P, Auyeung TW, Bahyah KS, et al. Sarcopenia in Asia: consensus report of the Asian working Group for Sarcopenia. J Am Med Dir Assoc. 2014;15(2):95-101. https://doi.org/10.1016/ j.jamda.2013.11.025.

19. Vilagut G, Forero CG, Barbaglia G, Alonso J. Screening for depression in the general population with the Center for Epidemiologic Studies Depression (CES-D): a systematic review with Meta-analysis. PLoS One. 2016;11(5): e0155431. https://doi.org/10.1371/journal.pone.0155431.

20. Ishikawa-Takata K, Ohta T, Tanaka H. How much exercise is required to reduce blood pressure in essential hypertensives: a dose-response study* Am J Hypertens. 2003;16(8):629-33. https://doi.org/10.1016/S0895-7061(03 )00895-1.

21. Moreland JD, Richardson JA, Goldsmith $\mathrm{CH}$, Clase CM. Muscle weakness and falls in older adults: a systematic review and Meta-analysis. J Am Geriatr Soc. 2004:52(7):1121-9. https://doi.org/10.1111/j.1532-5415.2004.52310.x.

22. Samuel D, Rowe P, Hood V, Nicol A. The relationships between muscle strength, biomechanical functional moments and health-related quality of life in non-elite older adults. Age Ageing. 2012;41(2):224-30. https://doi. org/10.1093/ageing/afr156.

23. Li R, Xia J, Zhang XI, Gathirua-Mwangi WG, Guo J, Li Y, et al. Associations of muscle mass and strength with all-cause mortality among US older adults. Med Sci Sports Exerc. 2018;50(3):458-67. https://doi.org/10.1249/MSS. 0000000000001448

24. Balachandran AT, Gandia K, Jacobs KA, Streiner DL, Eltoukhy M, Signorile JF. Power training using pneumatic machines vs. plate-loaded machines to improve muscle power in older adults. Exp Gerontol. 2017;98:134-42. https://doi.org/10.1016/j.exger.2017.08.009

25. Ferrara CM, McCrone SH, Brendle D, Ryan AS, Goldberg AP. Metabolic effects of the addition of resistive to aerobic exercise in older men. Int J Sport Nutr Exerc Metab. 2004;14(1):73-80. https://doi.org/10.1123/ ijsnem.14.1.73.

26. Quach L, Galica AM, Jones RN, Procter-Gray E, Manor B, Hannan MT, et al. The nonlinear relationship between gait speed and falls: the maintenance of balance, independent living, intellect, and zest in the elderly of Boston study. J Am Geriatr Soc. 2011;59(6):1069-73. https://doi.org/10.1111/j.15325415.2011.03408.x.

27. Artaud F, Singh-Manoux A, Dugravot A, Tzourio C, Elbaz A. Decline in fast gait speed as a predictor of disability in older adults. J Am Geriatr Soc. 2015; 63(6):1129-36. https://doi.org/10.1111/jgs.13442.

28. Heiland EG, Welmer A-K, Wang R, Santoni G, Angleman S, Fratiglioni L, et al. Association of mobility limitations with incident disability among older adults: a population-based study. Age Ageing. 2016;45(6):812-9. https://doi. org/10.1093/ageing/afw076.

29. Studenski S, Perera S, Patel K, Rosano C, Faulkner K, Inzitari M, et al. Gait speed and survival in older adults. Jama. 2011;305(1):50-8. https://doi.org/1 0.1001/jama.2010.1923

30. Hortobágyi T, Lesinski M, Gäbler M, VanSwearingen JM, Malatesta D, Granacher U. Effects of three types of exercise interventions on healthy old adults' gait speed: a systematic review and Meta-analysis. Sports Med. 2015; 45(12):1627-43. https://doi.org/10.1007/s40279-015-0371-2.

31. Lopopolo RB, Greco M, Sullivan D, Craik RL, Mangione KK. Effect of therapeutic exercise on gait speed in community-dwelling elderly people: a Meta-analysis. Phys Ther. 2006;86(4):520-40. https://doi.org/10.1093/ptj/86.4. 520.

32. Sayers SP, Bean J, Cuoco A, LeBrasseur NK, Jette A, Fielding RA. Changes in function and disability after resistance training: does velocity matter?: a pilot study. Am J Phys Med Rehabil. 2003;82(8):605-13. https://doi.org/10.1097/01. PHM.0000078225.71442.B6.

33. Brown M, Sinacore DR, Ehsani AA, Binder EF, Holloszy JO, Kohrt WM. Lowintensity exercise as a modifier of physical frailty in older adults. Arch Phys Med Rehabil. 2000;81(7):960-5. https://doi.org/10.1053/apmr.2000.4425.

34. Abdul Jabbar K, Seah W-T, Lau LK, Pang BW-J, Ng DH-M, Tan QL-L, et al. Fast gait spatiotemporal parameters in adults and association with muscle strength - the Yishun study. Gait Posture. 2021;85:217-23. https://doi.org/1 0.1016/j.gaitpost.2021.01.001

35. Uematsu A, Tsuchiya K, Kadono N, Kobayashi H, Kaetsu T, Hortobágyi T, et al. A behavioral mechanism of how increases in leg strength improve old adults' gait speed. PLoS One. 2014;9(10):e110350. https://doi.org/10.1371/ journal.pone.0110350.

36. Herold F, Törpel A, Schega L, Müller NG. Functional and/or structural brain changes in response to resistance exercises and resistance training lead to 
cognitive improvements - a systematic review. Eur Rev Aging Phys Act. 2019;16(1):10. https://doi.org/10.1186/s11556-019-0217-2.

37. Ng PEM, Nicholas SO, Wee SL, Yau TY, Chan A, Chng l, et al. Implementation and effectiveness of a multi-domain program for older adults at risk of cognitive impairment at neighborhood senior centres. Sci Rep. 2021;11(1):3787. https://doi.org/10.1038/s41598-021-83408-5.

38. Liu X, Seah JWT, Pang BWJ, Tsao MA, Gu F, Ng WC, et al. A single-arm feasibility study of community-delivered Baduanjin (qigong practice of the eight brocades) training for frail older adults. Pilot Feasibility Stud. 2020;6(1): 105. https://doi.org/10.1186/s40814-020-00649-3.

39. Tou NX, Wee S-L, Seah WT, Ng DHM, Pang BWJ, Lau LK, et al. Effectiveness of community-delivered functional power training program for frail and pre-frail community-dwelling older adults: a randomized controlled study. Prev Sci. 2021. https://doi.org/10.1007/s11121-021-01221-y.

40. Freiberger E, de Vreede $\mathrm{P}$, Schoene D, Rydwik E, Mueller V, Frändin K, et al. Performance-based physical function in older community-dwelling persons: a systematic review of instruments. Age Ageing. 2012;41(6):712-21. https:// doi.org/10.1093/ageing/afs099.

41. Lee IH, Park SY. Balance improvement by strength training for the elderly. J Phys Ther Sci. 2013;25(12):1591-3. https://doi.org/10.1589/jpts.25.1591.

42. Eckardt N. Lower-extremity resistance training on unstable surfaces improves proxies of muscle strength, power and balance in healthy older adults: a randomised control trial. BMC Geriatr. 2016;16(1):191. https://doi. org/10.1186/s12877-016-0366-3

43. Lee SY, Choo PL, Pang BWJ, Lau LK, Jabbar KA, Seah WT, et al. SPPB reference values and performance in assessing sarcopenia in communitydwelling Singaporeans - Yishun study. BMC Geriatr. 2021;21(1):213. https:/ doi.org/10.1186/s12877-021-02147-4.

44. Saida TGRH, Juul Sørensen T, Langberg H. Long-term exercise adherence after public health training in at-risk adults. Ann Phys Rehabil Med. 2017; 60(4):237-43. https://doi.org/10.1016/j.rehab.2017.02.006.

45. Bullard T, Ji M, An R, Trinh L, Mackenzie M, Mullen SP. A systematic review and meta-analysis of adherence to physical activity interventions among three chronic conditions: cancer, cardiovascular disease, and diabetes. BMC Public Health. 2019;19(1):636. https://doi.org/10.1186/s12889-019-6877-z.

46. Rodrigues IB, Armstrong JJ, Adachi JD, MacDermid JC. Facilitators and barriers to exercise adherence in patients with osteopenia and osteoporosis: a systematic review. Osteoporos Int. 2017;28(3):735-45. https://doi.org/10.1 007/s00198-016-3793-2.

47. McCambridge J, Witton J, Elbourne DR. Systematic review of the Hawthorne effect: new concepts are needed to study research participation effects. J Clin Epidemiol. 2014;67(3):267-77. https://doi.org/10.1016/j.jclinepi.2013.08. 015.

\section{Publisher's Note}

Springer Nature remains neutral with regard to jurisdictional claims in published maps and institutional affiliations.

Ready to submit your research? Choose BMC and benefit from:

- fast, convenient online submission

- thorough peer review by experienced researchers in your field

- rapid publication on acceptance

- support for research data, including large and complex data types

- gold Open Access which fosters wider collaboration and increased citations

- maximum visibility for your research: over $100 \mathrm{M}$ website views per year

At $\mathrm{BMC}$, research is always in progress.

Learn more biomedcentral.com/submissions 